\title{
Introduction to Information and Communication Technologies for Development (ICT4D): ICTs and Sustainable Development Minitrack
}

\author{
Jing Zhang \\ Clark University \\ jizhang@clarku.edu
}

\author{
Mathias Hatakka \\ Örebro University \\ mathias.hatakka@oru.se
}

\author{
Devinder Thapa \\ University of Agder \\ devinder.thapa@uia.no
}

In 2012 Walsham asked the question "Are we making a better world with ICTs?" and encouraged the IS community to explore how ICTs could help improve individual capabilities and opportunities to use technology to improve their lives. In the Information and communication technologies for development (ICT4D) field those questions are at the core. ICT4D focuses on the use of ICT to foster positive changes for individuals, communities or nations. The focus is on the lives of the poor and marginalized by improving aspects such as economy, health, security and education. The field is multidisciplinary and often includes theories from fields such as information systems, development studies, business and political science.

While it is widely acknowledged that ICTs can foster development, the question of how is still not fully understood. In addition, there is also a shortage in understanding the role of different stakeholders in development efforts using ICT. National government, non-government organizations (NGOs) and international donor agencies all play an important role. But we need a clearer understanding on the effectiveness of different development efforts undertaken by the different actors, and the role that different actors can and should have in the development process.

In this minitrack, we welcome theoretical and conceptual discussions as well as empirical studies with various methodologies. The papers should strive to provide future guidance to the field. We do not only look for success stories; criticism of the field and of existing approaches may be just as insightful as guidance for future efforts. Topics include, but are not limited to:
- Frameworks, and theoretical approaches for defining economic, social, and environmental sustainability in the context of ICT4D.

- Theoretical frameworks for guiding the development of ICT4D research and practice

- The roles of government, NGOs and international donor agencies in ICT4D.

- National ICT policies and strategies for sustainable development.

- Emerging technological innovations and their impacts on ICT4D.

- Organizational and inter-organizational structure and processes and their impacts on ICT4D.

- Case studies of government-led or public-private partnership ICT4D implementations

- Practical guidance for the development and implementation of ICT4D projects

- ICT roles in enabling citizens' participation in political discourses

- Assessment for ICT4D policies, programs, and interventions

- Digital divide and its consequences on sustainable development

- Environmental sustainability facilitated by ICT

- Projects/Case study illustrating the challenges/barriers, unintended consequences, and wicked problems of ICT4D, and ways of overcoming/mediating these problemsData analytics for sensing and identifying sustainable development challenges/problem and informing policy development

- Alignment of smart city/region planning and development in achieving sustainable goals

- Open data innovations in contributing to sustainable development 